\title{
The structure and properties of $\kappa$-carbides in duplex lightweight steels
}

\author{
W.J. Lu, X. F. Zhang, R.S. Qin* \\ Department of Materials, Imperial College London \\ Exhibition Road, London SW7 2AZ, United Kingdom
}

\begin{abstract}
$\kappa$-carbide in lightweight steel is studied. Its thermal stability, crystal morphology, orientation relationship, degree of lattice misfit and mechanical properties are measured experimentally. The mechanisms for the microstructural evolution of $\kappa$-carbide are considered based on the crystal structure, lattice misfit, element diffusivity, and solute partition. The hard $\gamma / \kappa$ grain and ductile $\alpha+\kappa$ grain provide an opportunity to develop the lightweight steels with desirable combination of mechanical properties.
\end{abstract}

Keywords: Lightweight steel; $\kappa$-carbide; Thermal stability; Lattice misfit; Morphology 
*Corresponding authors. Tel.: +44 (0)20 7594 6803; fax: +44 (0)20 75946757 . E-mail addresses: r.qin@imperial.ac.uk (R.S. Qin)

\section{Introduction}

Adding more aluminum (Al) and manganese $(\mathrm{Mn})$ to steels helps to reduce their mass density. The microstructural and mechanical properties of the lightweight steels change with $\mathrm{Al}$ and $\mathrm{Mn}$ compositions accordingly [1-2]. The formation of $\kappa-(\mathrm{Fe}, \mathrm{Mn})_{3} \mathrm{AlC}$ carbide (so called $\kappa$-carbide) is promoted by the addition of $\mathrm{Al}$ element $[3,4]$. Lightweight steels are found with ferrite-bases [3-5], austenite-based [3,6-7] and ferrite-austenite duplex-based microstructures [3,8-9]. $\kappa$-carbide is observed in every type of the high Al lightweight steels [3-10]. It plays an important role in affecting the mechanical properties of the steels [11]. (Fe,Mn) ${ }_{3} \mathrm{AlC}$ type carbide has a cubic perovskite crystal structure in which $\mathrm{Al}$ occupies corner positions, Fe and Mn occupy face-centered positions, and carbon is at the body center interstitial octahedral site [1]. This is different from that of $\gamma$-austenite face-centered-cubic crystal (fcc) and $\alpha$-ferrite body-centered-cubic crystal (bcc) phase in steels in terms of atom configuration.

The growth of same crystals from different crystallographic matrix provides an ideal situation to investigate the physics of pattern formation in patterned backgrounds [12]. Therefore, matrix $/ \kappa$ interface is strongly dependent on the matrix structure. Normally, $\gamma / \kappa$ interface is coherent, whereas $\alpha / \kappa$ interface is semicoherent. These suggest that 
lattice mismatch between matrix and $\kappa$-carbide depends on their interface. Interface anisotropy plays an important role in microstructural evolution, but the derivation of interface anisotropy from surface anisotropy is not a trivial task [13]. For lattice-misfit strain, it is easier to be measured by X-ray diffraction or selected area diffraction of transmission electron microscope. Thus, one can investigate the microstructural evolution based on measured lattice-misfit strain. The study helps to understand transformation kinetics, interface properties and microstructure-property relationship. $\kappa$-carbide can form in bcc ferrite phase and fcc austenite phase in duplex lightweight steel simultaneously. Systematic and quantitative study of the $\kappa$-carbide structure and properties are interesting to academia and engineering. This work devotes to the purpose.

\section{Experimental procedure}

A steel (800 g) with chemical composition of 9 wt.\% Al, 34 wt.\% Mn and 0.65 wt.\%

$\mathrm{C}$ was fabricated using induction melting furnace. The size of steel ingot was nominally $80 \mathrm{~mm} \times 50 \mathrm{~mm} \times 50 \mathrm{~mm}$ (length $\times$ width $\times$ height). A number of plates with $10 \mathrm{~mm}$ in thickness were cut from the middle of casts and then heat treated at $1200{ }^{\circ} \mathrm{C}$ for 4 hours in order to homogenize the chemical compositions before quenched in cold water. The plates were subsequently annealed at different temperatures $\left(600{ }^{\circ} \mathrm{C}, 700{ }^{\circ} \mathrm{C}\right.$ and $\left.800{ }^{\circ} \mathrm{C}\right)$ for 6 hours to allow the development of microstructure before quench into the cold water. Specimens were made from the quenched plates, grinded, polished and etched with $2 \%$ Nital. The grain morphology 
and chemical composition were analyzed using scanning electron microscope (SEM) equipped with energy dispersive X-ray spectroscopy (EDX). Phases were identified by X-ray diffraction (XRD) with scan rate $3^{\circ}$ per minute and scan step $0.02^{\circ}$. The volume fraction each phase were calculated by integration of all the diffraction peaks of the phase. The microstructure and crystal structure of the phases in the specimens were further characterized using the transmission electron microscope (TEM) with acceleration voltage of $200 \mathrm{kV}$. The TEM specimens were prepared by punching a 30 $\mu \mathrm{m}$ in thickness steel plate into $3 \mathrm{~mm}$ diameter disk and then polished using a twin-jet electro-polisher with a solution containing $10 \%$ perchloric acid and $90 \%$ acetic acid at $15{ }^{\circ} \mathrm{C}$. The Vickers hardness was measured using $1 \mathrm{~kg}$ load. The crystallographic structures and the lattice misfit between phases were calculated and plotted using commercial software - Crystal Maker.

\section{Results and discussion}

The SEM micrographs for the specimens annealed at $600{ }^{\circ} \mathrm{C}, 700{ }^{\circ} \mathrm{C}$ and $800{ }^{\circ} \mathrm{C}$ are presented in Figure 1(a)-(f), respectively. $\kappa$-carbide does not present in the steels quenched from $1200{ }^{\circ} \mathrm{C}$. The precipitation of $\mathrm{Al}, \mathrm{Mn}$ and $\mathrm{C}$ from the bulk phase at low temperature causes the formation of $\kappa$-carbide. In the steel annealed at $600{ }^{\circ} \mathrm{C}$, as illustrated in Figure 1(a) and (b), $\kappa$-carbide can be found in $\alpha$ phase with average size of $0.17 \pm 0.06 \mu \mathrm{m}$ but not in $\gamma$ phase. The reason for this is thought due to the low diffusivity of the elements in $\gamma$ phase than that in $\alpha$ phase. For example, it is reported in literature that the ratios of diffusivities of carbon in $\alpha$ to that in $\gamma$ phases are 629 at 
$730{ }^{\circ} \mathrm{C}, 5,493$ at $750{ }^{\circ} \mathrm{C}$ and 30,795 at $800{ }^{\circ} \mathrm{C}$ [14]. The high element mobility in $\alpha$ phase enables the formation of nano-scale $\kappa$-carbide at $600{ }^{\circ} \mathrm{C}$. However, the annealing time is not sufficient long to allow the formation of $\kappa$-carbide in $\gamma$ phase. In the steel annealed at $700^{\circ} \mathrm{C}$, as is shown in Figure $1(\mathrm{c})$ and (d), $\kappa$-carbides are in both $\alpha$ phase and $\gamma$ phase. The $\kappa$-carbide in $\alpha$ phase is coarsening to approximately $2.62 \pm$ $0.54 \mu \mathrm{m}$ in thickness. In some of the $\gamma$ phase grains, nano-scale $\kappa$-carbides are observed. Figure 1(e) and (f) show the microstructure of steels annealed at $800^{\circ} \mathrm{C}$. $\kappa$-carbides in $\alpha$ phase are further coarsening to approximately $17.2 \pm 4.5 \mu \mathrm{m} \mu \mathrm{m}$ in thickness. However, no $\kappa$-carbide is found in $\gamma$ phase. This shows that the thermal stability of $\kappa$-carbide in $\alpha$ phase is better than that in $\gamma$ phase in this steel. 

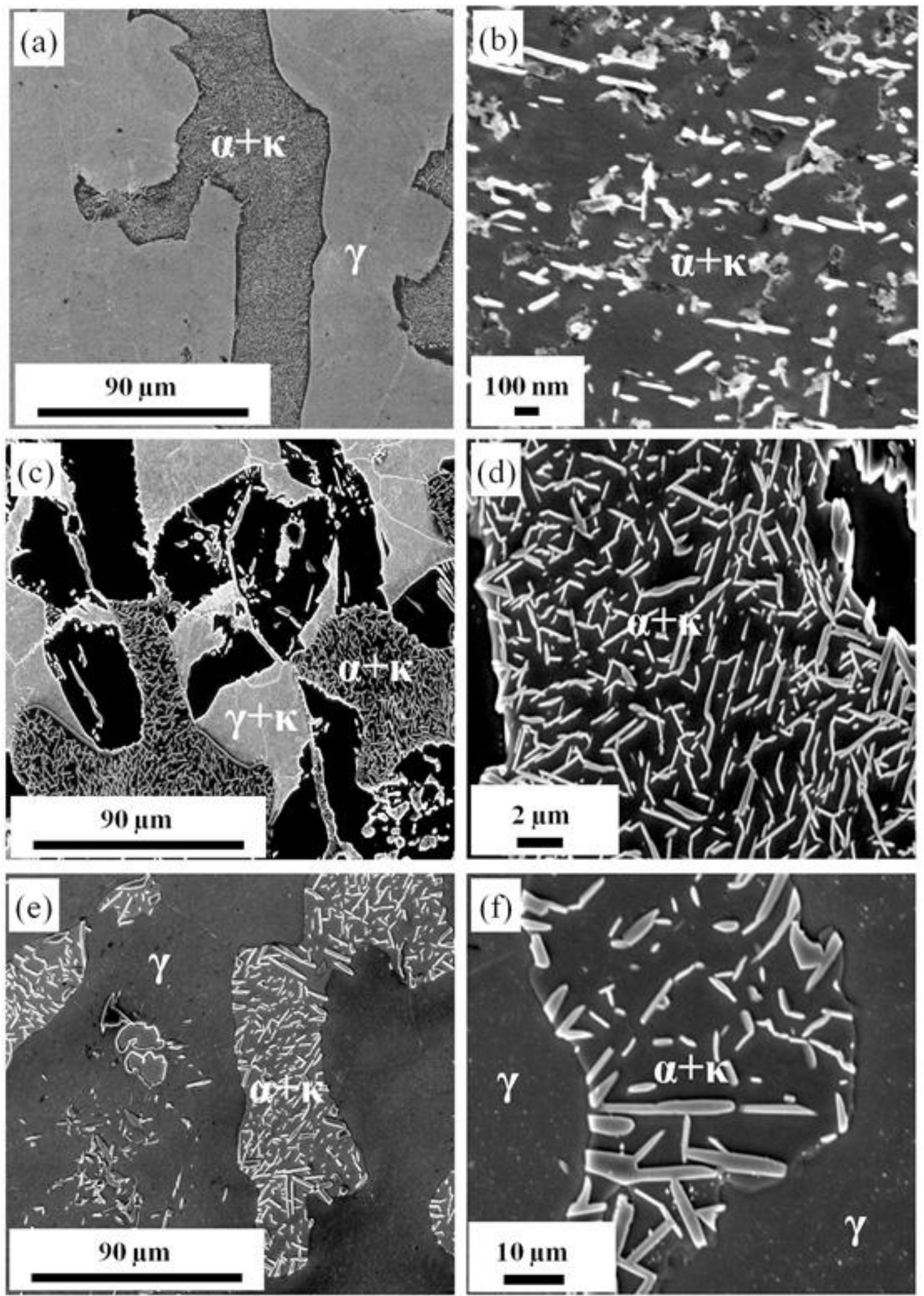

Figure 1 SEM micrographs for the steels annealed at (a) and (b) $600{ }^{\circ} \mathrm{C}$, (c) and (d) $700{ }^{\circ} \mathrm{C}$, and (e) and (f) $800{ }^{\circ} \mathrm{C}$ for 6 hours. 
High resolution SEM and TEM are implemented to further analyze the structure and property of $\kappa$-carbide in the steel annealed at $700{ }^{\circ} \mathrm{C}$. The results are presented in Figure 2. Figure 2(a) and 2(b) are the SEM and TEM bright field images for the $\kappa$-carbide in $\gamma$ phase. It is a typical microstructure formed in spinodal decomposition (e.g. the decomposition is determined solely by uphill diffusion, but does not experience the nucleation stage). Figure 2(c) and 2(d) are the SEM and TEM bright field images for the $\kappa$-carbide in $\alpha$ phase. The microstructure is typical of nucleation/growth controlled by diffusion. TEM diffraction pattern from the selected $\gamma / \kappa$ area is demonstrated in Figure 2(e). The calculations show a lattice distance of $\kappa$-carbide of $3.75 \AA$ and that of $\gamma$ phase of $3.66 \AA$. $\kappa$-carbide has a cube on cube orientation relationship with the $\gamma$ matrix with $(001)_{\kappa} / /(001)_{\gamma}$ and $[001]_{\kappa} / /[001]_{\gamma}$. The relationships are identical to that between $\gamma$ and $\gamma^{\prime}$ in Ni-based super alloys $[15,16]$. Figure 2(f) presents the TEM diffraction pattern from the selected $\alpha+\kappa$ area. The lattice distances of $\kappa$-carbide and $\alpha$ phases are $3.76 \AA$ and $2.87 \AA$ respectively. The orientation relationship between $\kappa$-carbide and $\alpha$ matrix grain are $(1 \overline{1} 1)_{\kappa} / /(110)_{\alpha}$ and $[011]_{\kappa} / /[001]_{\alpha}$. This obeys the Nishiyama-Wasserman relationship, and is in agreement with report in literature [17]. 

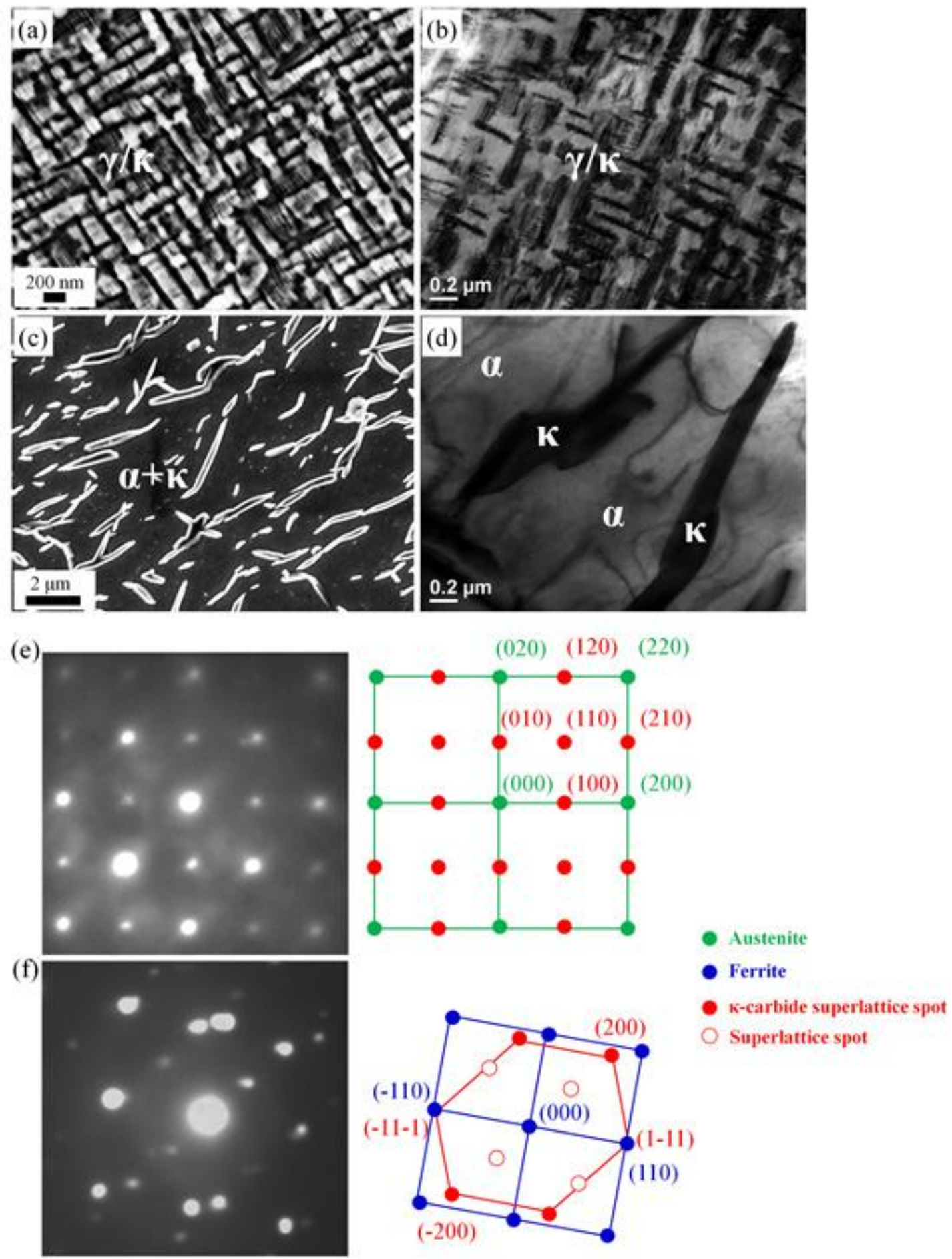

Figure 2 Experimental results for the steel annealed at $700^{\circ} \mathrm{C}$ for 6 hours (a) SEM image of fine $\kappa$-carbide in $\gamma$ phase; (b) TEM bright field image of fine $\kappa$-carbide in $\gamma$ phase; (c) SEM image of lamellar $\kappa$-carbide in $\alpha$ phase; (d) TEM bright field image of lamellar $\kappa$-carbide in $\alpha$ phase; (e) TEM diffraction pattern from the selected $\gamma / \kappa$ area; and (f) TEM diffraction pattern from the selected $\alpha+\kappa$ area. 
Figure 3(a) presents the XRD results for all the steels annealed at different temperatures. The volume fraction of $\gamma, \alpha$ and $\kappa$ phases are calculated according to Figure 3(a) and is plotted in Figure 3(b). The fraction of $\gamma$ phase decreases from 52.9 $\pm 2.5 \%$ at $600{ }^{\circ} \mathrm{C}$ to $45.6 \pm 2.8 \%$ at $700{ }^{\circ} \mathrm{C}$. The fraction of $\alpha$ changes from $40.1 \pm 1.2 \%$ to $31.3 \pm 3.2 \%$ and that of $\kappa$ from $7.0 \pm 1.3 \%$ to $23.3 \pm 2.2 \%$ in this temperature range. $\kappa$-carbide presents in both $\alpha$ and $\gamma$ grains at $700^{\circ} \mathrm{C}$. In order to improve the accuracy of Vickers hardness data for samples, 10 repeated times hardness test were conducted on the $\alpha$ and $\gamma$ phases in the steels annealed at various temperature and their average data were presented in Figure 3(c) with standard deviation. The $\gamma$ phase containing significant amount of $\kappa$-carbide demonstrates the highest hardness $(704 \pm 23 \mathrm{HV})$. The $\alpha$ phase annealed at this temperature shows a Vickers hardness of $526 \pm 20 \mathrm{HV}$. For the steel annealed at $800{ }^{\circ} \mathrm{C}, \gamma$ phase is $\kappa$-carbide free and has a Vickers hardness of $328 \pm 16 \mathrm{HV}$ only. This is even lower than that of $\alpha$ phase containing coarsening К-carbide $(348 \pm 14 \mathrm{HV})$. 

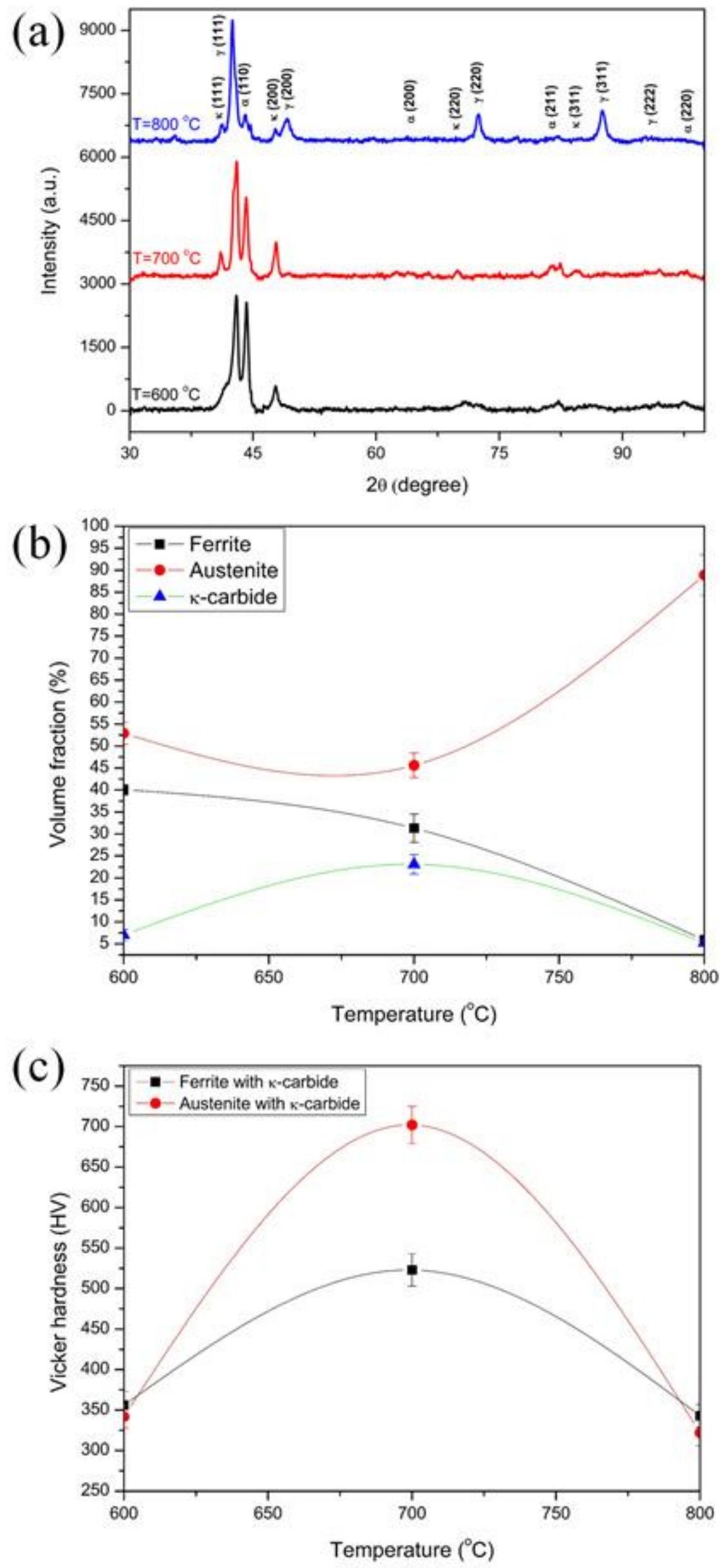
Figure 3 (a) XRD spectrum for the samples annealed at different temperatures; (b) The calculated volume fractions of $\alpha, \gamma$ and $\kappa$ phases; and (c) the Vickers hardness.

It has been noticed that some of the $\gamma$ phase grains have no but others have $\kappa$-carbides for the steel annealed at $700^{\circ} \mathrm{C}$. For an area arranged with $\alpha+\kappa$ grain, $\gamma / \kappa$ grain and $\gamma$ in a row, as demonstrated in Figure 4(a), EDX measurements were implemented to scan across the region linearly to characterize the element compositions, as demonstrated in Figure 4(b). $\alpha$ phase containing high $\mathrm{Al}$ and low Mn than that of in $\gamma$ phase. The $\gamma$ grain containing $\kappa$-carbides has higher $\mathrm{Al}$ and low $\mathrm{Mn}$ than that of the $\gamma$ grain with $\kappa$-carbides free. According to the literature, Sato et al observed the fine $\kappa$-carbide precipitation requiring the diffusion of both $\mathrm{C}$ and $\mathrm{Al}$ in austenite during a isothermal ageing treatment [22], whereas Sutou et al revealed the fine $\kappa$-carbide can be formed by rapid cooling from solution treatment via the diffusion of $\mathrm{Al}$ and $\mathrm{C}$ in the austenite [23]. Seol et al presented the fast diffusion of $\mathrm{C}$ and high content of $\mathrm{Al}$ partition are the key factors to form lamellar $\kappa$-carbide [24]. Al promotes $\kappa$-carbide formation and stabilizes $\kappa$-carbide presentation [4]. $\mathrm{C}$ is another element promotes and stabilizes $\kappa$-carbide [18]. High $\mathrm{C}$ diffusivity in $\alpha$ phase contributes to $\kappa$-carbide nucleation at low temperature [14]. Low C solubility in $\alpha$ phase may help to stabilize the $\kappa$-carbide at high temperature. Therefore, for the current study, the formation of fine $\kappa$-carbide via spinodal decomposition in austenite might be controlled by the diffusion of slowest diffusing alloying elements $\mathrm{Al}$ and $\mathrm{Mn}$ rather than $\mathrm{C}$, whereas the 
nucleation of lamellar $\kappa$-carbide are mainly controlled by $\mathrm{C}$ diffusion and $\mathrm{Al}$ partitioning in ferrite.

Crystal Maker software has been implemented to plot the unit cells of $\gamma$ phase, $\alpha$ phase and $\kappa$-carbide. A model is applicable to predict the lattice misfit of these phases [19]. According to the orientation relationships between phases revealed by TEM (Figure 3(e)-(f)), a $2 \times 2 \times 2 \gamma$ unit cells in (001) plane along [001] direction has been constructed. This can be overlapped with a $2 \times 2 \times 2 \kappa$-carbide unit cells in (001) plane along [001] direction. The results are plotted in Figure 4(c), where the black solid circles represent $\gamma$ phase and red open circles $\kappa$-carbide. The lattice misfit along $[001]_{\kappa} / /[001]_{\gamma}$ is calculated to be $2.70 \%$. Similarly, a $2 \times 2 \times 2 \alpha$ unit cells in (110) plane along [001] direction and a $2 \times 2 \times 2 \kappa$-carbide unit cells in (1 $\overline{1} 1)$ plane along [011] direction had been constructed and overlapped, as demonstrated in Figure 4(d). The blue solid circles represent $\alpha$ phase and red open circles the $\kappa$-carbide. The calculated lattice misfit along $[011]_{\kappa} / /[001]_{\alpha}$ is $6.67 \%$. 


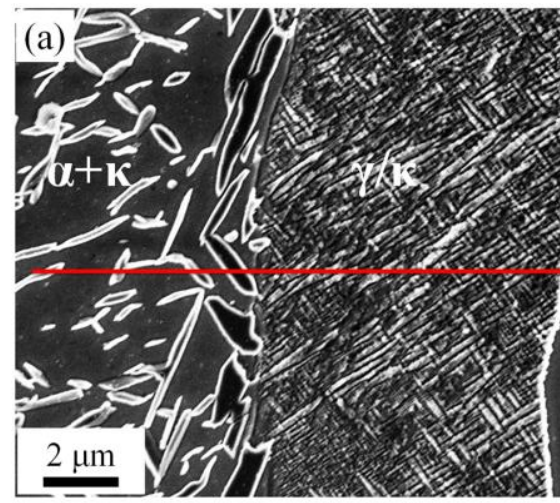

(c) 250

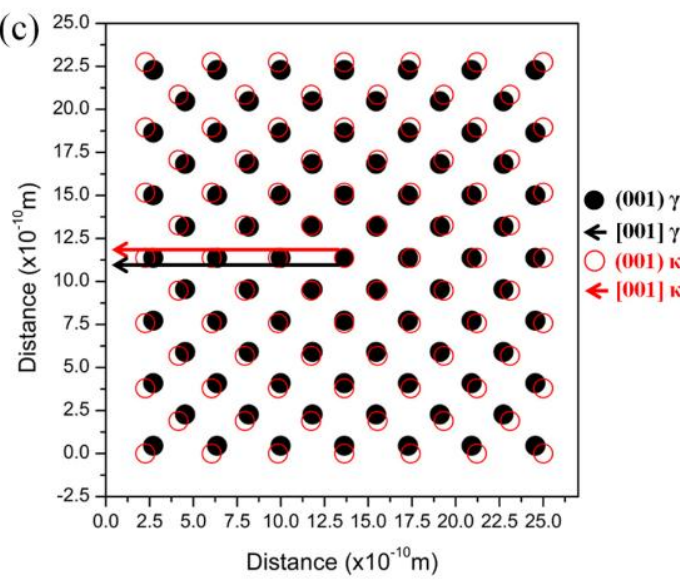

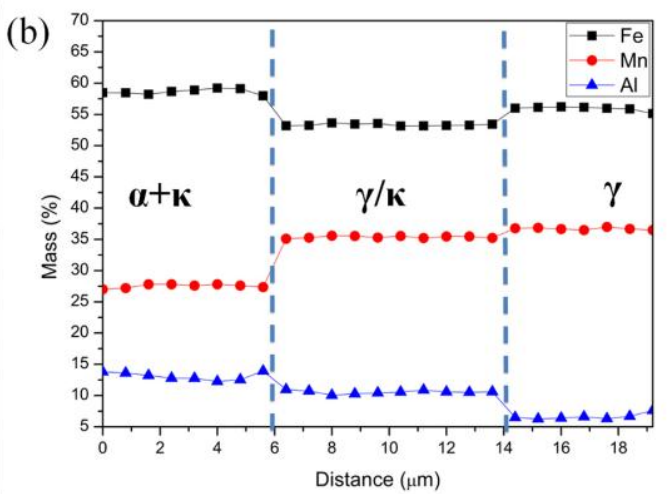

(d)

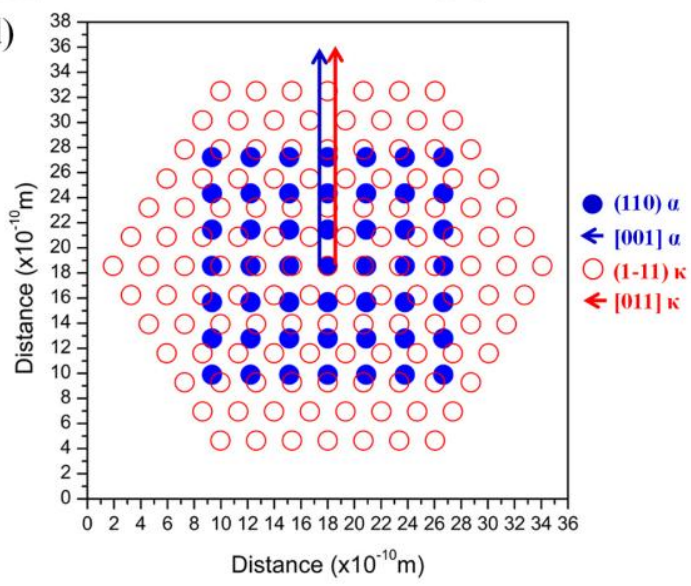

Figure 4 (a) SEM micrograph for an area consisting of $\kappa+\alpha, \kappa / \gamma$ and $\gamma$ phases; (b) The chemical compositions across the area; (c) planar lattice matching diagrams for $2 \times 2 \times 2$ cells between $\kappa$-carbide and $\gamma$ phase; and (d) planar lattice matching diagrams for $2 \times 2 \times 2$ cells between $\kappa$-carbide and $\alpha$ phase.

The low lattice misfit between $\kappa$-carbide and $\gamma$ grain is able to produce excellent mechanical properties $[1,20,21]$. On the other side, the low lattice misfit means small elastic strain energy. The strain energy is the kinetic barrier in first order phase transition. The small strain energy enables the spinodal decomposition at small undercooling. Thus nano-scale phase can be formed under low lattice-misfit strain in spinodal decomposition, as shown in Figure 2(a). The strength of $\gamma / \kappa$ is therefore high. Oppositely, the high lattice misfit between $\kappa$-carbides and $\alpha$ phase made the strain 
energy significant. The large misfit brings down the mechanical property of $\kappa+\alpha$ phase. The high strain energy is a big barrier for $\kappa$-carbides nucleation. Spinodal decomposition is therefore not possible in such a case. However, the high diffusivity in $\alpha$ phase accelerates the diffusional growth. The observed $\kappa$-carbide microstructure in $\alpha$ phase is therefore coarse at high temperature.

From the literature [1], the overall phase transformation is $\gamma \rightarrow \gamma_{o}+\kappa^{\prime} \rightarrow \alpha+\kappa$ in austenitic Fe-30Mn-7.8Al-1.3C steel after aging at $550{ }^{\circ} \mathrm{C}$ for $48800 \mathrm{~min}$ (approximately 4 months). The fine $\kappa$-carbide $\left(\kappa^{\prime}\right)$ precipitated in austenite at the beginning of ageing treatment. When the time is longer enough, the phases consisting of fine $\kappa$-carbide and austenite were transformed into ferrite and lamellar $\kappa$-carbide. In our experiment, the steel sample (Fe-34Mn-9Al-0.65C) is duplex (ferrite-austenite) microstructure, which is different from the fully austenitic microstructure of steel [1]. This implies that fine $\kappa$-carbide and lamellar $\kappa$-carbide can precipitates in austenite and ferrite, respectively. Since the ageing time in our experiment (360 min) is much lower than that in preious experiment [1], the fine $\kappa$-carbide and austenite might have not enough time to convert to lamellar $\kappa$-carbide and ferrite in austenite. Thus, the precipitation of fine $\kappa$-carbide and lamellar $\kappa$-carbide were be observed in austenite and ferrite simultaneously at aged $700{ }^{\circ} \mathrm{C}$ for $360 \mathrm{~min}$. When the temperature was heated up to $800{ }^{\circ} \mathrm{C}$, the most of fine $\kappa$-carbide was transformed back into austenite and the lamellar $\kappa$-carbide was continuously coarsen.

\section{Conclusions}


The microstructure of $\mathrm{Fe}-34 \mathrm{Mn}-9 \mathrm{Al}-0.65 \mathrm{C}$ steels annealed at $600^{\circ} \mathrm{C}, 700^{\circ} \mathrm{C}$ and $800^{\circ} \mathrm{C}$ has been studied. The volume fractions of $\alpha, \gamma$ and $\kappa$ phases at the temperature range have been characterized. $\kappa$-carbides are more stable in $\alpha$ phase than that in $\gamma$ phase. The lattice misfit between $\kappa$-carbide and $\gamma$ is low $(2.70 \%)$. This leads to low strain energy and hence enables spinodal decomposition. The spinodal decomposition leads to the formation of nano-scale phase. The mechanical property of $\gamma / \kappa$ phase is high due to the fine microstructure and low misfit. The lattice misfit between $\kappa$-carbide and $\alpha$ is high $(6.67 \%)$. The growth mechanism for $\kappa$-carbide in $\alpha$ phase is via nucleation rather than spinodal decomposition. The diffusivity of $\mathrm{C}$ in $\alpha$ phase causes significant coarsening of $\kappa$-carbide. The overall mechanical property of duplex lightweight steel is determined by the microstructure of $\alpha, \gamma$ and $\kappa$ phases. Design the thermomechanical processing in order to generate the suitable microstructure can lead to the manufacturing of lightweight steels with desirable combination of mechanical properties.

\section{Acknowledgement}

The authors gratefully acknowledge the financial support from TATA Steel, Royal Academy of Engineering and EPSRC (No. EP/J011460/1) at United Kingdom.

\section{References}

[1] W.K. Choo, J.H. Kim and J.C. Yoon: Acta Mater, 1997, 45, 4877-4885.

[2] A. Etienne, V. Massardier-Jourdan, S. Cazottes, X. Garat, M. Soler, I. Zuazo and X. 
Kleber: Metall. Mater. Trans. A, 2013, 45, 324-334.

[3] H. Kim, D.W. Suh and N.J. Kim: Sci. Technol. Adv. Mater, 2013, 14, 014205.

[4] Y.H. Heo, Y.Y. Song, S.J. Par, H.K.D.H. Bhadeshia and D.W. Suh: Metall. Mater. Trans. A, 2012, 43, 1731-1735.

[5] J. Herrmann, G. Inden and G. Sauthoff: Acta Mater, 2003, 51, 2847-2857.

[6] I. Gutierrez-Urrutia and D. Raabe: Acta Mater, 2012, 60, 5791-5902.

[7] K. Choi, C.H. Seo, H. Lee, S.K. Kim, J.H. Kwak, K.G. Chin, K.T. Park and N.J. Kim: Scr. Mater, 2010, 63, 1028-1031.

[8] C.H. Seo, K.H. Kwon, K. Choi, K.H. Kim, J.H. Kwak, S. Lee and N.J. Kim: Scr. Mater, 2012, 66, 519-522.

[9] S.S. Sohn, B.J. Lee, S. Lee, N.J. Kim and J.H. Kwak: Acta Mater, 2013, 61, 5050-5066.

[10] D. Raabe, H. Springer, I. Gutierrez-Urrutia, F. Roters, M. Bausch, J.-B. Seol, M. Koyama, P.-P. Choi and K. Tsuzaki: JOM, 2014, 66, 1845-1856.

[11] W.J. Lu, X.F. Zhang and R.S. Qin: Mater. Lett, 2015, 138, 96-99.

[12] H.K.D.H. Bhadeshia and R. Honeycombe, Steel - Microstructure and Properties ( $3^{\text {rd }}$ Edition), Elsevier, London, 2006.

[13] L.Granasy, T. Pusztai, T.Borzsonyi, J.A. Warren and J.F. Douglas: Nature Mater, 2004, 3, 645-650.

[14] T. Akbay and C. Atkinson: J. Mater. Sci, 1996, 31, 2221-2226.

[15] Y. Kimura, K. Handa, K. Hayashi and Y. Mishima: Intermetallics, 2004, 12, 607-617. 
[16] K. Ishida, H. Ohtani, N. Satoh, R. Kainuma and T. Nishizawa: ISIJ Int, 1990, 30, 680-686.

[17] S.Y. Han, S.Y. Shin, H.J. Lee, S. Lee, N.J. Kim and J.H. Kwak: Metall. Mater. Trans. A, 2011, 43, 843-853.

[18] K. Sato, K. Tagawa and Y. Inoue: Metall. Mater. Trans. A, 1990, 21, 5-11.

[19] B.L. Bramfitt: Metall. Trans, 1970, 1, 1987-1995.

[20] K. Lu, L. Lu and S. Suresh: Science, 2009, 324, 349-352.

[21] L.N. Bartlett, D.C.V. Aken, J. Medvedeva, D. Isheim, N.I. Medvedeva and K. Song: Metall. Mater. Trans. A, 2014, 45, 2421-2435.

[22] Y. Sutou, N. Kamiya, R. Umino, L. Ohnuma and K. Ishida: ISIJ Int, 2010, 50, 893-899.

[23] J.B. Seol, D. Raabe, P. Choi, H.S. Park, J.H. Kwak and C.G. Park: Scr. Mater, 2013, 68, 348-353. 
